\title{
Distinct effects of etoposide on glutamine-addicted neuroblastoma
}

\author{
Kadri Valter $^{1} \cdot$ Polina Maximchik $^{2} \cdot$ Alibek Abdrakhmanov $^{2} \cdot$ Viacheslav Senichkin $^{2} \cdot$ Boris Zhivotovsky $^{1,2}$. \\ Vladimir Gogvadze ${ }^{1,2}$ (i)
}

Received: 27 October 2018 / Revised: 9 July 2019 / Accepted: 15 July 2019 / Published online: 7 August 2019

(c) The Author(s) 2019

\begin{abstract}
The majority of anticancer drugs are DNA-damaging agents, and whether or not they may directly target mitochondria remains unclear. In addition, tumors such as neuroblastoma exhibit addiction to glutamine in spite of it being a nonessential amino acid. Our aim was to evaluate the direct effect of widely used anticancer drugs on mitochondrial activity in combination with glutamine withdrawal, and possible apoptotic effects of such interaction. Our results revealed that etoposide inhibits mitochondrial respiratory chain Complex I causing the leakage of electrons and the superoxide radical formation. However, it was not sufficient to induce apoptosis, and apoptotic manifestation was detectable only alongside the withdrawal of glutamine, a precursor for antioxidant glutathione. Thus, the simultaneous depletion of glutathione and destabilization of mitochondria by ROS can compromise the barrier properties of the mitochondrial membrane, leading to cytochrome $c$ release and the activation of the mitochondrial apoptotic pathway. Thus, the depletion of antioxidants or the inhibition of the pathways responsible for cellular antioxidant response can enhance mitochondrial targeting and strengthen antitumor therapy.
\end{abstract}

Keywords Apoptosis $\cdot$ Neuroblastoma $\cdot$ Mitochondria $\cdot$ Oxidative stress $\cdot$ Respiratory chain

\section{Introduction}

Tumor development can be counteracted by the stimulation of apoptosis or other forms of programmed cell death [1, 2]. In the majority of tumor cells, apoptotic pathways are dormant owing to the low expression of pro-apoptotic factors, such as pro-apoptotic members of Bcl-2 family proteins $[3,4]$, or glycolytic shift, described by Otto Warburg, which stimulates glycolysis in tumor cells and silences mitochondria $[5,6]$.

Mitochondria are paramount in the stimulation/execution of apoptosis. Targeting mitochondria and the stimulation of mitochondrial apoptotic pathway has proven to be a

\section{Electronic supplementary material The online version of this} article (https://doi.org/10.1007/s00018-019-03232-z) contains supplementary material, which is available to authorized users.

Vladimir Gogvadze

Vladimir.Gogvadze@ki.se

1 Division of Toxicology, Institute of Environmental Medicine, Karolinska Institutet, Box 210, 17177 Stockholm, Sweden

2 Faculty of Medicine, MV Lomonosov Moscow State University, 119991 Moscow, Russia promising strategy in tumor cell elimination [7, 8]. Mitochondria can be targeted by compounds that affect mitochondrial activity and/or contribute to the outer mitochondrial membrane (OMM) permeabilization, which may lead to the activation of programmed cell death. Various conventionally used anticancer therapeutic drugs are DNA-damaging agents, but their ability to target mitochondria remains unclear.

Targeting the mitochondrial electron transport chain can influence proton gradient formation and instigate the dissipation of the mitochondrial membrane potential $(\Delta \psi)$. Furthermore, obstructions in respiratory chain electron flow can induce electron leakage and the formation of reactive oxygen species (ROS) [9-12]. These events can cause OMM permeabilization, leading to cytochrome $c$ release and the activation of apoptosis. Although mitochondria are regarded as a source of ROS, they also possess a powerful detoxifying system responsible for ROS elimination [13]. Moreover, in some studies, mitochondria are regarded as "a sink for ROS generated in other cellular compartments", because they can also rapidly detoxify ROS [14]. Thus, the ability of mitochondria to diminish ROS constitutes an important factor regulating apoptosis induction. 
In addition to glycolytic shift, some tumors display addiction to glutamine, even though this is a nonessential amino acid [15]. Attained glutamine is converted by glutaminase into glutamate, which is used as an important pre-substrate for the Krebs cycle, synthesis of glutathione, and amino and fatty acids to support intensive proliferation of cancer cells $[16,17]$. One such glutamine-dependent tumor is neuroblastoma (NB), the most common solid cancer in childhood, which is often driven by oncogene MYCN amplification [18, 19]. MYCN is a transcription factor that belongs to the family of MYC oncoproteins. MYC and MYCN are involved in glutaminolysis. Thus, suppression of MYC in human glioma SF188 cells using shRNA caused the reduction in glutamine consumption and ammonia production [20]. Knockdown of MYCN inhibited glutaminolysis in NB cells, while overexpression of MYCN in neural crest progenitor cells enhanced glutaminolysis [21]. Therefore, targeting glutaminolysis might be beneficial for tumor cell elimination.

Our aim was to evaluate the direct effect of widely used anticancer drugs on mitochondrial activity in combination with glutamine withdrawal, and the possible apoptotic effects of such interaction.

\section{Materials and methods}

\section{Cell lines}

TET21N derived from SHEP cells possess an inducible expression system on the basis of the tetracycline repressor of $E$. coli to reversibly express MYCN in a human NB cell line [22]. TET2 $1 \mathrm{~N}$ cell line was cultured in $37^{\circ} \mathrm{C}$ humidified air/ $\mathrm{CO}_{2}(5 \%)$ atmosphere with RPMI 1640 (Sigma) complete medium including heat-inactivated fetal calf serum $10 \%$ (w/v), penicillin/streptomycin (100 U/ml), $100 \mu \mathrm{g} / \mathrm{ml}$ hygromycin B, and $200 \mu \mathrm{g} / \mathrm{ml}$ geneticin. Glutamine deprivation was achieved by changing the regular medium to glutamine-free RPMI 1640 (Sigma) $24 \mathrm{~h}$ prior to treatment. Switching off the oncogene MYCN was done by incubation of the cells with $0.1 \mu \mathrm{g} / \mathrm{ml}$ doxycycline $24 \mathrm{~h}$ before seeding the sample plates. HCT116 cell line was cultured in $37{ }^{\circ} \mathrm{C}$ humidified air $/ \mathrm{CO}_{2}(5 \%)$ atmosphere with DMEM $\left(\right.$ Gibco $\left.^{\circledR}\right)$ complete medium including heat-inactivated fetal calf serum $10 \%(\mathrm{w} / \mathrm{v})$ and penicillin/streptomycin $(100 \mathrm{U} / \mathrm{ml})$.

\section{Mitochondrial oxygen consumption}

15,000 cells/well were seeded on 96-well plates (Seahorse Bioscience, Billerica, MA) and allowed to adhere overnight. The attached cells were washed with Seahorse assay medium and incubated in the same medium $(0.175 \mathrm{ml})$ for $1 \mathrm{~h}$ at $37^{\circ} \mathrm{C}$. Respiration analysis began with the assessment of basal oxygen consumption rate (OCR), followed by the injection of various drugs into the wells. The compounds of interest were injected from port $\mathrm{A}$, and subsequent additions from ports $\mathrm{B}$ to $\mathrm{D}$ were oligomycin, carbonyl cyanide 3-chlorophenylhydrazone (CCCP), and rotenone plus antimycin A. Injections from B to D were conducted to respectively assess phosphorylating respiration, spare respiratory capacity, and non-mitochondrial respiration. The data were normalized to the protein content of each well.

In addition, oxygen consumption was measured in cells with permeabilized plasma membrane using an oxygen electrode (Hansatech Instruments, Norfolk, UK). Cells were harvested and resuspended in KCl-based buffer, containing $5 \mathrm{mM} \mathrm{KH}_{2} \mathrm{PO}_{4}, 1 \mathrm{mM} \mathrm{MgCl} 2,5 \mathrm{mM}$ Tris (pH 7.5), and mild detergent digitonin $(0.01 \%)$. The mitochondrial Complex I substrates pyruvate and malate, or Complex II substrate succinate together with rotenone to block Complex I activity, were supplemented. Measurements were analyzed using OxygraphPlus software (Hansatech Instruments, Norfolk, UK).

\section{Mitochondrial transmembrane potential $(\Delta \psi)$}

The mitochondrial transmembrane potential $(\Delta \psi)$ was measured once the cells had been loaded with mitochondria-accumulating fluorescent tetramethylrhodamine ethyl ester (TMRE, $25 \mathrm{nM}$, Molecular Probes ${ }^{\circledR}$ ) dye. The cells were incubated with TMRE for $20 \mathrm{~min}$ at $37^{\circ} \mathrm{C}$, trypsinized, resuspended in HEPES buffer containing $25 \mathrm{nM}$ TMRE, and analyzed by BD Accuri ${ }^{\mathrm{TM}} \mathrm{C} 6$ flow cytometer.

\section{Mitochondrial ROS}

Mitochondrial superoxide production was detected by staining cells with MitoSOX ${ }^{\mathrm{TM}}$ Red (Molecular Probes ${ }^{\circledR}$ ) dye according to the manufacturer's protocol and analyzed using the BD Accuri ${ }^{\mathrm{TM}} \mathrm{C} 6$ flow cytometer.

\section{Alterations in cytosolic $\mathrm{Ca}^{2+}$}

Cells were loaded with fluorescent $\mathrm{Ca}^{2+}$ indicator dye Fluo-4 $\left(2 \mu \mathrm{M}, 30 \mathrm{~min}\right.$, Molecular Probes $\left.{ }^{\circledR}\right)$, and washed and incubated in indicator-free medium for $30 \mathrm{~min}$. Samples were subsequently subjected to harvesting and flow cytometer analysis by $\mathrm{BD}$ Accuri ${ }^{\mathrm{TM}} \mathrm{C} 6$.

\section{Western-blot analysis}

The samples were collected, mixed with Laemmli's loading buffer, and boiled for $10 \mathrm{~min}$. The proteins of interest were separated by a $10-15 \%$ sodium dodecyl sulfate polyacrylamide gel electrophoresis (SDS-PAGE). Electroblotting to nitrocellulose was conducted for $1.5 \mathrm{~h}$ at $120 \mathrm{~V}$, followed 
by $5 \%$ non-fat milk phosphate-buffered saline (PBS) blocking for $1 \mathrm{~h}$ at room temperature. Having been washed with PBS $(3 \times, 10 \mathrm{~min})$, primary antibodies were added for overnight incubation at $4{ }^{\circ} \mathrm{C}$. The membranes were rinsed and incubated with secondary antibodies (1:7000) for $1.5 \mathrm{~h}$ and the blots were visualized by Licor ${ }^{\circledR}$ Odyssey ${ }^{\circledR}$ CLx Imaging System or X-ray film.

Cytochrome $c$ release was detected once the samples were permeabilized in digitonin-containing fractionation buffer $\left(150 \mathrm{mM} \mathrm{KCl}, 1 \mathrm{mM} \mathrm{MgCl}{ }_{2}, 0.2 \mathrm{mM}\right.$ EGTA, $0.05 \%$ digitonin, $5 \mathrm{mM}$ Tris, and $\mathrm{pH} 7.5$ ) for $15 \mathrm{~min}$ at RT. Following centrifugation at 13,400 rpm for $5 \mathrm{~min}$, the samples were separated into supernatant and pellet fractions, mixed with Laemmli's buffer and analyzed using the previously described immunodetection protocol.

The samples' protein concentration was assessed by Pierce bicinchoninic acid (BCA) colorimetric assay in accordance with the manufacturer's instructions using a VersaMax ${ }^{\mathrm{TM}}$ microplate reader. The following primary antibodies were used: cytochrome $c$ (556433, BD Biosciences), PARP (11835238001, ROCHE), C-PARP (5625, Cell Signaling), GLS1 (ab156876, Abcam), GLS2 (ab113509, Abcam), p53 (sc-126, Santa Cruz), BID (611528, BD Biosciences), and GAPDH (Trevigen).

\section{Measurement of caspase-3-like activity}

The cells were harvested and resuspended in PBS at RT. $15 \mu \mathrm{l}$ of the suspension were added in triplicate to 96-well plate and frozen at $-20{ }^{\circ} \mathrm{C}$. The remaining suspension was used for protein concentration analysis by BCA protein assay. For caspase-3-like activity assay, $50 \mu \mathrm{l}$ of peptide substrate buffer (100 mM HEPES, 10\% sucrose, 0.1\% Chaps, $5 \mathrm{mM}$ DTT, $0.001 \%$ NP-40, and $40 \mu \mathrm{M}$ DEVD-AMC) was added into each well of the thawed samples. Caspase-3-like activity was measured by detecting the caspase- 3 mediated cleavage of DEVD-AMC and the release of fluorogenic 7-amino-4-methylcoumarin (AMC) in a fluorometric assay. Data were obtained using a Fluoroscan II plate reader (Labsystems), with excitation at 355-nm and emission at 460-nm wavelengths. The fluorescence results were normalized by protein content.

\section{Measurement of glutathione content}

The content of glutathione in aliquots of cells was assessed as soluble SH groups [23] after precipitation of proteins by equal amount of 5\% trichloroacetic acid, followed by centrifugation at $6500 \times g$ for $5 \mathrm{~min}$. The supernatant was transferred into a 96-well plate, $100 \mu \mathrm{l}$ of $0.5 \mathrm{M}$ Tris buffer (pH 8.9) and $20 \mu \mathrm{l}$ of DTNB were added and incubated for $10 \mathrm{~min}$. The absorbance was measured at $412 \mathrm{~nm}$ using a VersaMax ${ }^{\mathrm{TM}}$ microplate reader.

\section{Statistics}

All of the data presented were based on at least three repetitions and represent the average results. The error bars represent SD. Statistical significance was assessed by Student's $t$ test (two-tailed distribution, two-sample unequal variance) or two-way ANOVA $(* p<0.05$ and $* * p<0.01)$.

\section{Results}

\section{The effect of anticancer drugs on oxygen consumption rate (OCR)}

To evaluate the immediate effect of anticancer drugs on mitochondrial functions, assessment of the oxygen consumption rate (OCR) was performed in TET $21 \mathrm{~N}$ cells. After evaluation of basal respiration, cisplatin, doxorubicin, or etoposide was injected into the wells. Neither cisplatin nor doxorubicin had an immediate effect on the respiration rate, whereas etoposide caused a rapid decrease in OCR (Fig. 1a). Figure 1a represents a typical mitochondrial OCR test. After recording the basal oxygen consumption, oligomycin was used to analyze phosphorylating respiration, the uncoupler carbonyl cyanide $\mathrm{m}$-chlorophenylhydrazone (CCCP) to assess the spare respiratory capacity, and rotenone plus antimycin to measure non-mitochondrial oxygen consumption. The suppression of respiration by etoposide was observed not only in TET $21 \mathrm{~N}$ cells, but also in HCT116 colon carcinoma cell line (Fig. 1b). Thus, the inhibition of respiration by etoposide is a common consequence for various cell lines. Assessment of OCR in TET21N cells after 6 and $18 \mathrm{~h}$ of etoposide treatment revealed its decrease as the apoptosis progressed (Supplementary Fig. 1a, b).

\section{The effect of etoposide on the respiratory complexes}

To elucidate which complexes of the mitochondrial respiratory chain are affected by etoposide, oxygen consumption was evaluated in cells with digitonin-permeabilized plasma membrane, enabling mitochondria to be provided with substrates for Complex I (pyruvate and malate) or Complex II (succinate). The results obtained revealed an immediate and severe suppression of Complex I upon the addition of etoposide both before (solid line) and after (dashed line) mitochondrial uncoupling with the protonophore CCCP (Fig. 1c). At the same time, no significant instantaneous effect on the Complex II activity after adding etoposide was detected (Fig. 1d). The assessment of the continuous etoposide treatment $(6 \mathrm{~h}$ and $18 \mathrm{~h})$ revealed a restoration of Complex I 

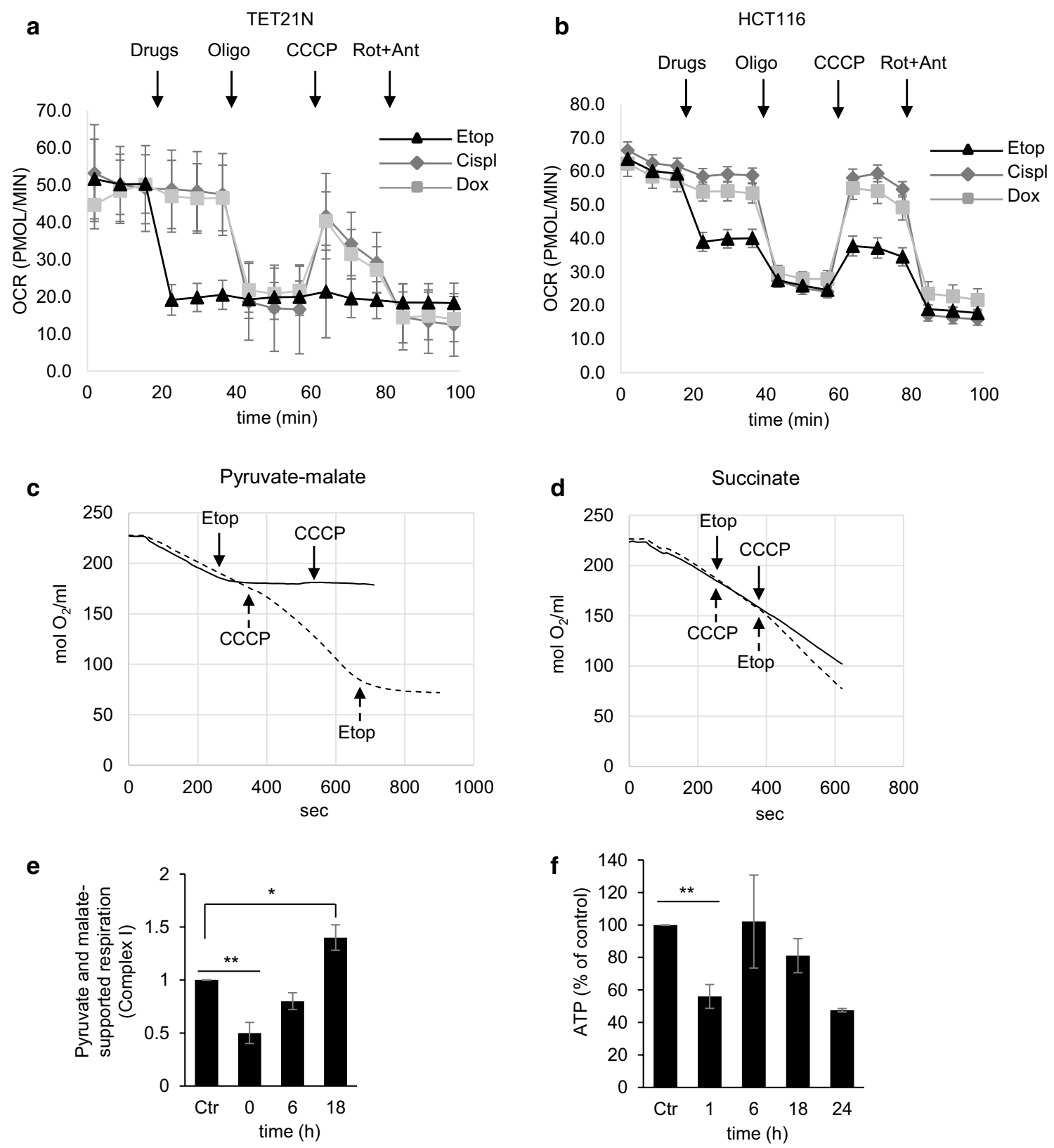

Fig. 1 The effect of various anticancer drugs on oxygen consumption rate (OCR). a Assessment of the immediate effect of anticancer drugs on oxygen consumption in TET21N and HCT116 (b) cells. Oligomycin (Oligo) was used to analyze phosphorylating respiration, the uncoupler CCCP to assess spare respiratory capacity, and rotenone (Rot) plus antimycin (Ant) to estimate non-mitochondrial oxygen consumption. Etop etoposide, Cisp cisplatin, Dox doxorubicin; c immediate effect of etoposide $(34 \mu \mathrm{M})$ on respiration, sup-

activity to initial level after $6 \mathrm{~h}$ of incubation with etoposide (Fig. 1e). The suppression of oxygen consumption correlated with the level of ATP (Fig. 1f). The initial decrease in ATP level, which observed $1 \mathrm{~h}$ after etoposide administration, was followed by its restoration after $6 \mathrm{~h}$. After $18 \mathrm{~h}$, the

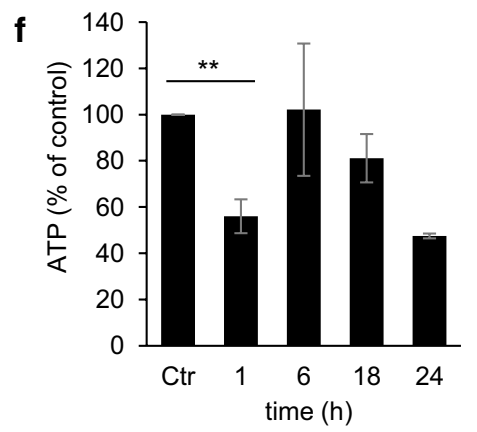

ported by pyruvate and malate (Complex I), or succinate (Complex II) (d). Solid line corresponds to solid arrows and dotted line to dotted arrows indicating the order of drug administration; e oxygen consumption supported by Complex I substrates after $0 \mathrm{~h}, 6 \mathrm{~h}$, and $18 \mathrm{~h}$ of treatment with etoposide $(34 \mu \mathrm{M})$. The experiments $\mathbf{c}-\mathbf{e}$ were performed using cell with digitonin-permeabilized plasma membrane; $\mathbf{f}$ assessment of ATP content at different time points in TET21N cells treated with etoposide $(34 \mu \mathrm{M}) .{ }^{*} p<0.05, * * p<0.01$

content of ATP was decreased again, apparently because of progressing cell death. 


\section{The effect of etoposide on cellular $\mathrm{Ca}^{2+}$ content}

The direct effect of etoposide on respiration and the deterioration of mitochondria may compromise cellular $\mathrm{Ca}^{2+}$ homeostasis and trigger pathological processes [24, 25]. To answer the question whether etoposide can affect cellular $\mathrm{Ca}^{2+}$ homeostasis, the level of cytosolic $\mathrm{Ca}^{2+}$ was assessed using the fluorescent $\mathrm{Ca}^{2+}$ indicator dye Fluo-4. The results did not detect any immediate effect of etoposide on the cytosolic $\mathrm{Ca}^{2+}$ level (Fig. 2a). However, elevation of the cytosolic $\mathrm{Ca}^{2+}$ was observed after $24 \mathrm{~h}$ treatment with etoposide (Fig. 2b), apparently was due to the processes related to cell death execution. As positive control, $0.1 \mu \mathrm{M}$ of ionophore A23187 was used. The ionophore caused a transient increase of intracellular $\mathrm{Ca}^{2+}$ (Fig. 2a, dotted line). a

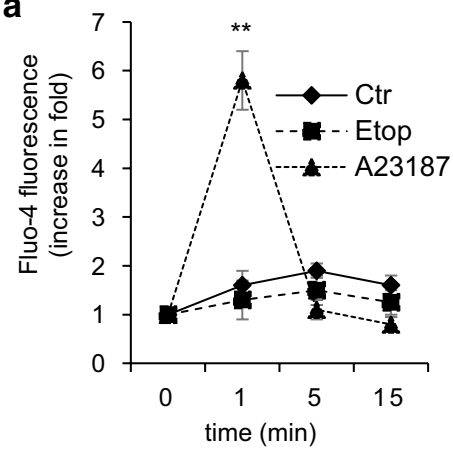

C

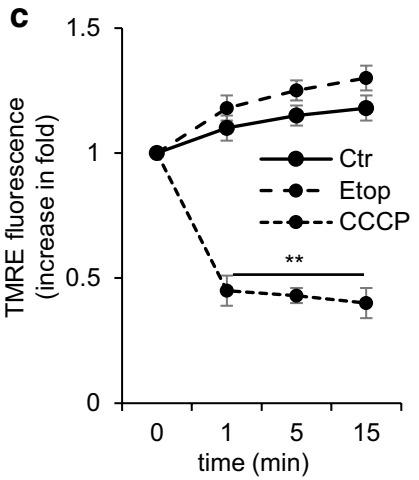

b

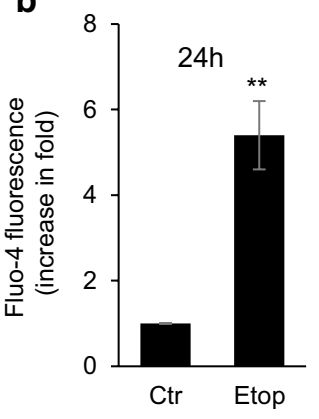

d

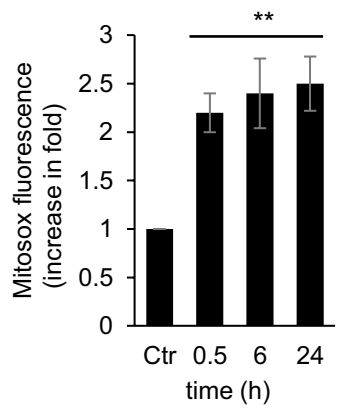

Fig. 2 The effect of etoposide on cellular $\mathrm{Ca}^{2+}$ content, mitochondrial $\Delta \psi$, and superoxide production in TET21N cells analyzed by flow cytometry. a $\mathrm{Ca}^{2+}$ content after etoposide $(34 \mu \mathrm{M})$ addition detected with Fluo-4 dye, A23187 (0.1 $\mu \mathrm{M})$ used as a positive control; b $\mathrm{Ca}^{2+}$ content after treatment with etoposide $(34 \mu \mathrm{M})$ for $24 \mathrm{~h}$, detected with Fluo-4; $\mathbf{c}$ mitochondrial $\Delta \psi$ after etoposide $(34 \mu \mathrm{M})$ addition detected with TMRE staining, CCCP used as a negative control; $\mathbf{d}$ superoxide production after $0.5 \mathrm{~h}, 6 \mathrm{~h}$, and $24 \mathrm{~h}$ of treatment with etoposide $(34 \mu \mathrm{M})$ detected with superoxide-sensitive dye MitoSox ${ }^{\mathrm{TM}}$ Red. $* p<0.05, * * p<0.01$
The effect of etoposide on mitochondrial $\Delta \psi$ and superoxide production

Inhibition of the respiratory chain can compromise proton gradient formation, which will lead to attenuation of the mitochondrial $\Delta \psi$. Assessment of $\Delta \psi$ in TET2 $1 \mathrm{~N}$ cells was performed by staining cells with cationic fluorescent dye TMRE (tetramethylrhodamine ethyl ester), which accumulates in energized mitochondria. The measurements demonstrated that etoposide's suppression of the respiratory chain has a minor impact on $\Delta \psi$ (Fig. 2c). Nevertheless, the obstruction of Complex I in combination with changes in $\Delta \psi$ can cause a leakage of electrons and the formation of superoxide radical [26]. To test this possibility, the assessment of mitochondrial superoxide production following etoposide administration was performed. The addition of etoposide to TET21N cells triggered ROS formation as early as $0.5 \mathrm{~h}$ after administration, which remained exalted after $6 \mathrm{~h}$ and 24 h (Fig. 2d).

\section{The effect of glutamine removal on etoposide-induced apoptosis in TET21N cells}

The suppression of mitochondrial respiration and stimulation of ROS production can potentially lead to mitochondrial deterioration and triggering the mitochondrial apoptotic pathway. However, we could detect only relatively modest manifestations of apoptosis after $6 \mathrm{~h}$ of etoposide treatment (Fig. 3a-e). Although mitochondria are regarded as a source of ROS, they also possess a powerful detoxifying system responsible for the elimination of oxygen radicals. One of the most important cellular endogenous antioxidants is the tripeptide glutathione. Therefore, reducing glutathione levels may enhance the deleterious effects of ROS and compromise the barrier properties of mitochondrial membranes, leading to cytochrome $c$ release and the activation of the mitochondrial apoptotic pathway. Given that the cells in our experiment were grown in the presence of glutamine, a precursor of glutathione, and mitochondrial substrate of $\alpha$-ketoglutarate [17], glutamine withdrawal may attenuate the level of the antioxidant and stimulate etoposide-induced apoptosis when the respiratory chain is blocked and ROS production is triggered. To test this possibility, TET21N cells were cultured for $24 \mathrm{~h}$ in the presence or absence of glutamine and treated subsequently with etoposide for $6 \mathrm{~h}$ and $24 \mathrm{~h}$ (the experiment scheme is shown in Supplementary Fig. 2), followed by the analysis of several manifestations of apoptosis.

The results obtained with glutamine-deprived cells after $6 \mathrm{~h}$ of exposure to etoposide indeed revealed the stimulation of cell death assessed by cytochrome $c$ release from mitochondria (Fig. 3a), caspase-3-like activity (Fig. 3b), cleavage of PARP (Fig. 3c, d), and the 
Fig. 3 The effect of glutamine removal on etoposide-induced apoptosis in TET $21 \mathrm{~N}$ cells. a cytochrome $c$ release after 6 and $24 \mathrm{~h}$ of etoposide treatment in the presence and absence of glutamine; b caspase-3-like activity in glutamine-supported and -deprived cells after $6 \mathrm{~h}$ and $24 \mathrm{~h}$ treatment with etoposide and the protective effect of the antioxidant $\mathrm{N}$-acetylcysteine (NAC); c cleavage of PARP in glutamine-supported and glutamine-deprived cells after $6 \mathrm{~h}$ and $24 \mathrm{~h}$ of treatment with etoposide and densitometry of the corresponding blot (d); e phosphatidylserine externalization in cells treated with etoposide $(34 \mu \mathrm{M})$ in the presence or absence of glutamine after 6 and $24 \mathrm{~h}$ of incubation
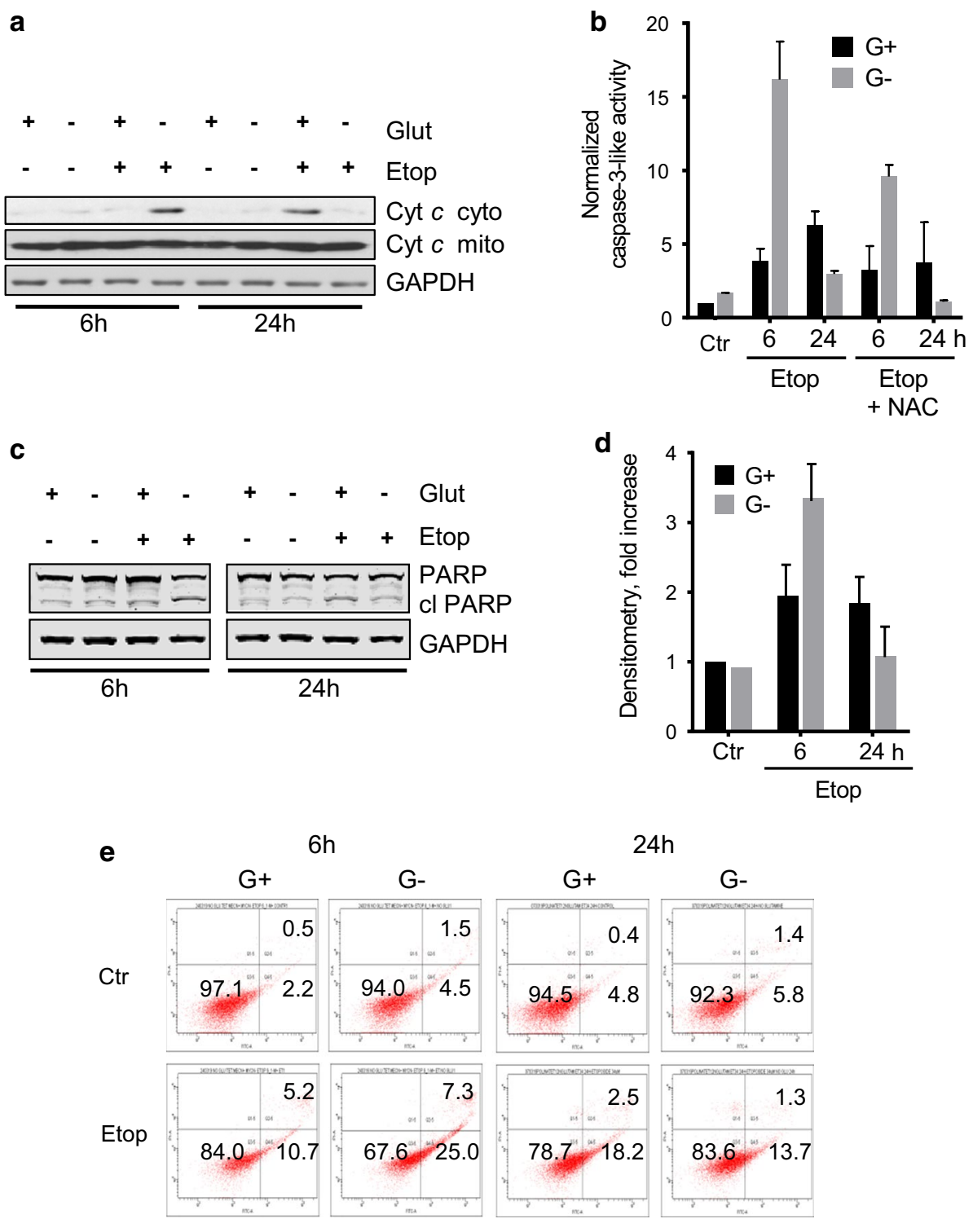

appearance of phosphatidylserine on the outer leaflet of plasma membrane tested with staining with Annexin V and propidium iodide (PI) (Fig. 3e). Withdrawal of glutamine markedly stimulated apoptosis assessed by all these parameters. The cell death stimulation detected in glutamine-deprived cells was dependent on ROS, because the antioxidant $N$-acetylcysteine significantly suppressed caspase-3-like activity in glutamine-deprived samples (Fig. 3b). A similar result was obtained with another antioxidant trolox, a water-soluble analog of vitamin E, after both 6 and $24 \mathrm{~h}$ of treatment with etoposide (Supplementary Fig. 3). After $24 \mathrm{~h}$ of etoposide treatment, as we have shown earlier [27], withdrawal of glutamine suppressed etoposide-induced apoptosis (Fig. 3a-e).
To test whether cell death stimulation is a consequence of impaired antioxidant defense, the level of glutathione was assessed after removal of glutamine. Indeed, glutamine deprivation for $6 \mathrm{~h}$ attenuated the glutathione content (Fig. 4a) both in control- and etoposide-treated cells. To prove the importance of antioxidant defense in apoptosis progression, depletion of glutathione was performed using buthionine sulfoximine (BSO). BSO stimulated cell death triggered by 34 and $50 \mu \mathrm{M}$ etoposide assessed by PARP cleavage (Fig. 4b). 


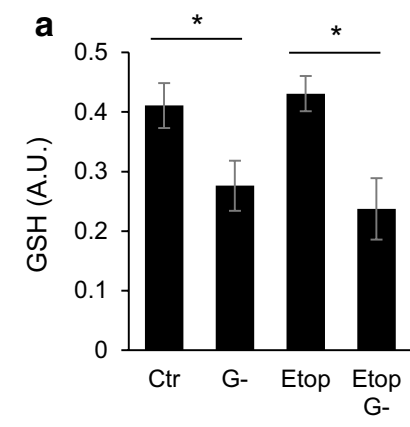

b

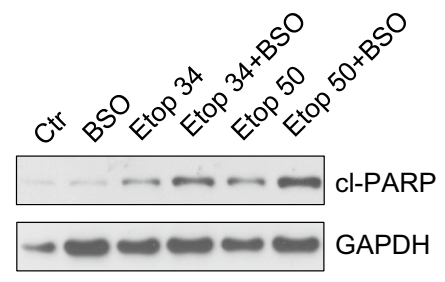

Fig. 4 Involvement of glutathione in apoptotic response of TET21N cells. a The level of glutathione in TET $21 \mathrm{~N}$ cells treated with etoposide $(34 \mu \mathrm{M})$ for $6 \mathrm{~h}$ in the presence and absence of glutamine, $* p<0.05$. b glutathione depletion by $200 \mathrm{nM}$ buthionine sulfoximine (BSO) stimulates etoposide-induced apoptosis a

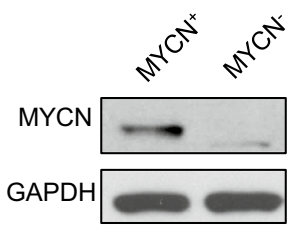

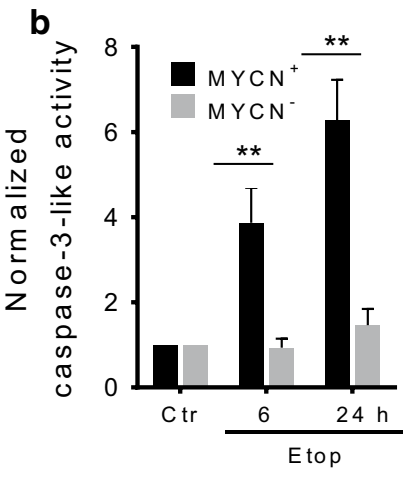

d

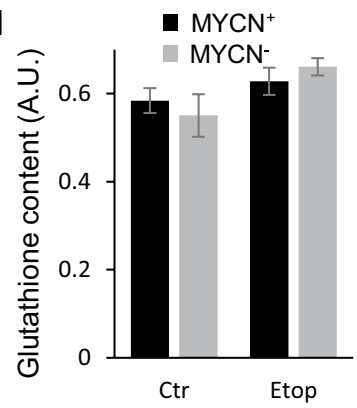

Fig. 5 The effect of etoposide on $\mathrm{MYCN}^{+}$and $\mathrm{MYCN}^{-}$TET21N cells. a The level of MYCN in TET21N cells without and with doxycycline treatment; $\mathbf{b}$ caspase-3-like activity in $\mathrm{MYCN}^{+}$and $\mathrm{MYCN}^{-}$ TET $21 \mathrm{~N}$ cells after $6 \mathrm{~h}$ and $24 \mathrm{~h}$ of etoposide treatment; c GLS1 and GLS2 expression in glutamine-supported and -deprived $\mathrm{MYCN}^{+}$ and $\mathrm{MYCN}^{-}$TET21N cells; $\mathbf{d}$ glutathione content in $\mathrm{MYCN}^{+}$and $\mathrm{MYCN}^{-}$TET $21 \mathrm{~N}$ cells treated with etoposide for $6 \mathrm{~h}$. Concentration of etoposide- $34 \mu \mathrm{M} ; * p<0.05, * * p<0.01$

\section{The effect of glutamine removal on etoposide-induced apoptosis in MYCN-deficient cells}

Glutamine is converted into glutamate, a precursor of glutathione, by the enzyme glutaminase. This enzyme is a target of oncogene MYCN, and downregulation of MYCN expression should attenuate the level of glutathione and subsequently enhance the sensitivity of cells to ROS. Thus, the consequence of "switching off" MYCN before etoposide treatment was analyzed. Incubation of TET21N cells with doxycycline for $24 \mathrm{~h}$ downregulated MYCN expression completely (Fig. 5a). Surprisingly, in comparison to the MYCN-amplified cells $\left(\mathrm{MYCN}^{+}\right)$, the absence of MYCN $\left(\mathrm{MYCN}^{-}\right.$cells) markedly suppressed etoposide-induced apoptosis both after $6 \mathrm{~h}$ and $24 \mathrm{~h}$ of etoposide treatment, verified by caspase-3-like activity (Fig. 5b) and phosphatidylserine externalization after staining with Annexin $\mathrm{V}$ and PI (Supplementary Fig. 4). Removal of glutamine stimulated apoptosis in $\mathrm{MCYN}^{-}$cells as it has been shown for $\mathrm{MYCN}^{+}$ cells (Supplementary Fig. 4). Therefore, further analysis was performed to reveal the mechanisms behind this finding.

Unexpectedly, the comparison of glutaminase 1 and 2 (GLS1/2) expression in $\mathrm{MYCN}^{+}$and $\mathrm{MYCN}^{-}$cells did not reveal any difference (Fig. 5c). In addition, there was no decrease in the content of glutathione. In $\mathrm{MYCN}^{-} \mathrm{TET} 21 \mathrm{~N}$ cells, a modest non-significant increase in glutathione level was observed after $6 \mathrm{~h}$ incubation with etoposide (Fig. 5d).

Analysis of oxygen consumption in $\mathrm{MYCN}^{+}$and $\mathrm{MYCN}^{-}$TET2 $1 \mathrm{~N}$ cells revealed that switching MYCN off significantly decreased OCR in TET21N cells (Fig. 6a) and markedly altered respiratory response to glutamine deprivation (Fig. 6b). Thus, in $\mathrm{MYCN}^{+}$cells, withdrawal of glutamine suppressed OCR by 60-70\%, whereas in $\mathrm{MYCN}^{-}$cells, which are supposedly less addicted to glutamine, OCR inhibition was not so prominent (30-35\%) (Fig. 6c). Treatment of $\mathrm{MYCN}^{-}$TET21N cells with etoposide, revealed a similar ATP decrease-increase-decrease pattern (Supplementary Fig. 5a) as already shown for $\mathrm{MYCN}^{+}$cells in Fig. 1f. Glutamine deprivation decreased the level of ATP in both $\mathrm{MYCN}^{+}$and $\mathrm{MYCN}^{-}$TET21N cells. Etoposide treatment for $24 \mathrm{~h}$ further decreased the ATP content, although the difference between $\mathrm{MYCN}^{+}$and MYCN $^{-}$TET21N cells was insignificant (Supplementary Fig. 5b). Furthermore, in $\mathrm{MYCN}^{+}$TET21N cells, glutamine withdrawal prominently hampered cell proliferation (Fig. 6c). In contrast, $\mathrm{MYCN}^{-}$TET21N cells, which demonstrated only partial OCR suppression after glutamine withdrawal, were able to proliferate further, although the intensity of cell division was restricted (Fig. 6d).

Apparently, due to the lower rate of oxygen consumption, superoxide production in $\mathrm{MYCN}^{-}$cells upon treatment with etoposide was diminished as compared to $\mathrm{MYCN}^{+}$ 
Fig. 6 The comparison of the effect of glutamine removal on $\mathrm{MYCN}^{+}$. and $\mathrm{MYCN}^{-}$TET21N cells: a switching off MYCN decreases OCR in TET21N cells; $\mathbf{b}$ attenuation of OCR after glutamine removal in $\mathrm{MYCN}^{+}$and $\mathrm{MYCN}^{-}$TET21N cells in percentage to control. OCR was calculated as the difference between mitochondrial oxygen consumption uncoupled by CCCP (maximal) and non-mitochondrial respiration, after inhibiting respiratory chain with rotenone plus antimycin; $\mathbf{c ~} \mathrm{MYCN}^{+}$TET21N cell proliferation in the presence and absence of glutamine; $\mathbf{d ~} \mathrm{MYCN}^{-}$TET2 $1 \mathrm{~N}$ cell proliferation in the presence and absence of glutamine; e, stimulation of superoxide radical production in etoposide-treated $\mathrm{MYCN}^{+}$and $\mathrm{MYCN}^{-}$TET21N cells assessed by flow cytometry using superoxide-sensitive dye MitoSox ${ }^{\mathrm{TM}}$ Red in the presence and absence of glutamine, and the effect of antioxidant NAC on this process; $\mathrm{f}$, glutathione content in $\mathrm{MYCN}^{+}$ and $\mathrm{MYCN}^{-}$TET21N cells in the presence and absence of glutamine treated with etoposide for $6 \mathrm{~h}$. Concentration of etoposide-34 $\mu \mathrm{M}$; ${ }^{*} p<0.05, * * p<0.01$

TET21N cells (Fig. 6e). Glutamine deprivation stimulated superoxide production in $\mathrm{MYCN}^{+}$TET21N cells and to a lesser extent in $\mathrm{MYCN}^{-}$cells. Antioxidant NAC did not affect superoxide production neither in $\mathrm{MYCN}^{+}$nor in $\mathrm{MYCN}^{-}$TET21N cells irrespectively of the presence of glutamine. Removal of glutamine decreased the level of glutathione in $\mathrm{MYCN}^{+}$TET21N cells, but had no effect in $\mathrm{MYCN}^{-}$cells (Fig. 6e). Treatment of glutamine-deprived cells with etoposide attenuated the level of glutathione in $\mathrm{MYCN}^{+}$and $\mathrm{MYCN}^{-}$TET21N cells to the same extent.

In addition, we analyzed apoptotic response upon glutamine withdrawal in other cell lines with different levels of MYCN expression, in particular, MYCN expressing SK$\mathrm{N}-\mathrm{BE}(2)$ cells, and SH-SY5Y cells, in which expression of MYCN is low (Supplementary Fig. 6a). In SK-SN-BE(2) cells, glutamine withdrawal stimulated apoptosis after $6 \mathrm{~h}$ of treatment, but attenuated after $24 \mathrm{~h}$, similarly to TET2 1 $\mathrm{MYCN}^{+}$cells (Supplementary Fig. 6b). At the same time, death of SH-SY5Y cells did not show any dependence on glutamine. It should be mentioned, however, that these cells were far more sensitive to etoposide; ten times lower concentration of the drug was sufficient to induce death of SHSY5Y cells.

\section{Discussion}

The majority of anticancer drugs are aimed at nuclear DNA for tumor cell elimination. Cell death is activated when DNA damage stabilizes the transcriptional factor p53, which regulates the expression of various pro-apoptotic proteins involved in OMM permeabilization and the release of mitochondrial pro-apoptotic factors. Pro-apoptotic, BH3-only Bcl-2 family proteins, such as Bax, Puma, Noxa, and possibly Bid, are direct transcriptional targets of p53. In addition, p53 may also act in a transcription-independent manner through binding to pro-apoptotic Bcl-2-family proteins, leading to permeabilization of mitochondria. p53, itself, a
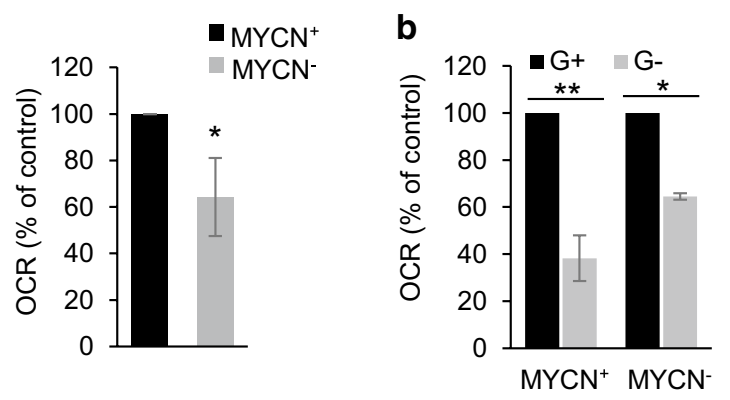

C

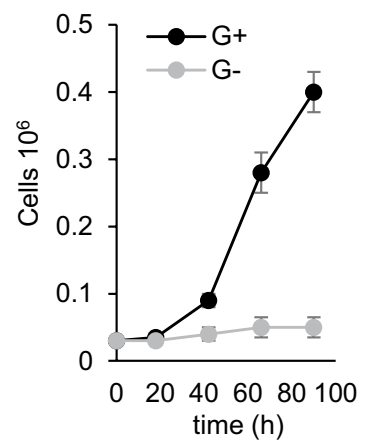

d

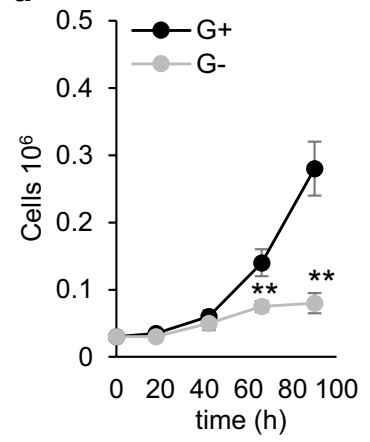

e

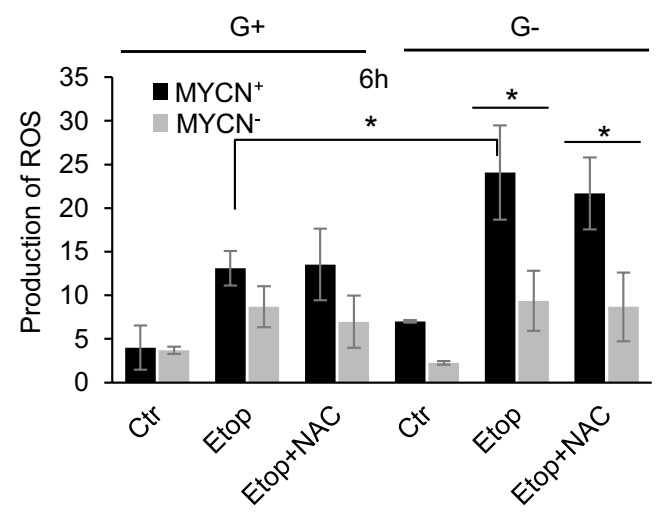

f

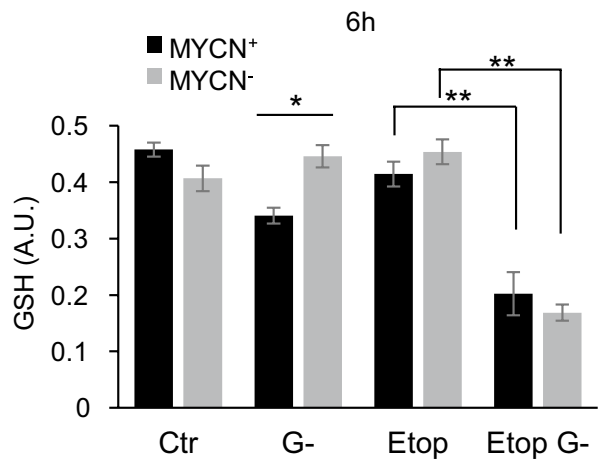

may also act like a BH3-only protein and antagonize Bcl-2 function (reviewed in [28]). However, the question whether anticancer drugs can directly affect mitochondria has yet to be thoroughly investigated. We found that among conventionally used anticancer drugs, only etoposide was able to target mitochondria directly. Etoposide suppressed Complex I of the mitochondrial respiratory chain (Fig. 1c), causing 
the leakage of the electrons, and formation of superoxide radicals (Fig. 2d).

Stimulation of oxidative stress is an important tool for tumor cell death initiation. Elevated levels of ROS have been noticed in the majority of cancers, where they facilitate numerous aspects of tumor development, progression, and metastases [13]. At the same time, tumors demonstrate higher levels of ROS-detoxifying enzymes relative to normal cells. This is necessary to prevent ROS-mediated activation of death-inducing pathways [29]. Therefore, depletion of water- and lipid-soluble antioxidants in cancer cells would allow for the accumulation of excessive amounts of ROS to the levels that initiate toxicity and reduce tumorigenesis [30]. Although elevated ROS production can trigger mitochondrial deterioration and apoptosis in tumor cells [31], alterations in the mitochondrial respiratory chain after $6 \mathrm{~h}$ of etoposide treatment induced only modest cell death (Fig. 3a-e). The manifestations of various characteristic features of apoptosis after $6 \mathrm{~h}$ of treatment only became evident upon the withdrawal of glutamine (Fig. 3a-e) that was mediated by the decrease in the content of the antioxidant glutathione (Fig. 4a). Depletion of glutathione by BSO enhanced etoposide-induced apoptosis (Fig. 4b). The suppression of apoptosis upon glutamine withdrawal $24 \mathrm{~h}$ after etoposide treatment (Fig. 3a-e), as we have shown earlier, correlates with downregulation of p53 in these cells [27]. A scheme representing these different pathways and their relationships is shown in Fig. 7. Apoptosis induced by etoposide is a complex process involving several factors. In a traditional model, etoposide induces DNA damage with the subsequent stabilization of p53, and triggers p53-dependent apoptosis. Previously observed suppression

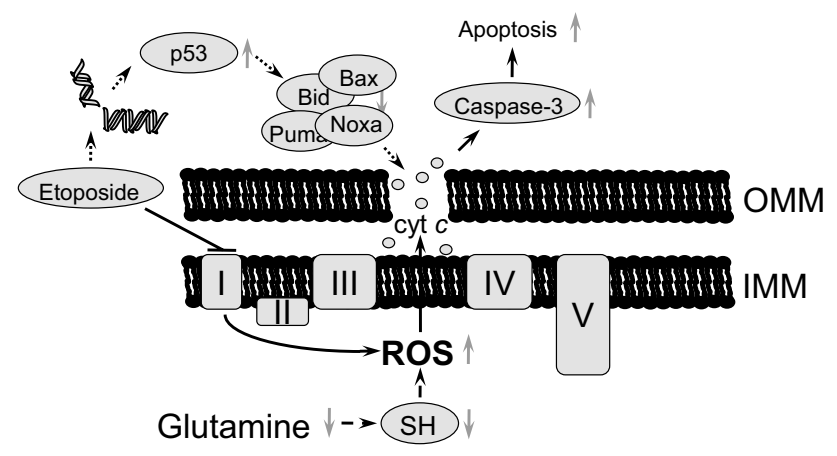

Fig. 7 Schematic representation of possible pathways involving etoposide treatment and glutamine deprivation in TET21N cells. Etoposide has an immediate effect (black arrows) on mitochondrial respiratory chain Complex I that triggers ROS production, cytochrome $c$ release and modest apoptosis induction. This effect can be increased by glutamine deprivation (dashed arrows). Long-term $(24 \mathrm{~h})$ etoposide treatment (dotted arrows) leads to DNA damagedependent p53 stabilization and OMM permeabilization. OMM outer mitochondrial membrane; IMM inner mitochondrial membrane of apoptosis upon $24 \mathrm{~h}$ of treatment with etoposide and glutamine withdrawal was linked to the downregulation of p53 level, a target of MYCN [27]. At the same time, etoposide also suppresses Complex I of the mitochondrial respiratory chain and induces the production of ROS. However, the powerful mitochondrial antioxidant defense system protects cells from excessive ROS and prevents cell death. In contrast, glutamine deprivation and subsequent glutathione depletion may lead to the activation of apoptotic pathways and potentiate tumor cell elimination.

Glutamine metabolism is known to be regulated by the oncogene MYC and MYCN, which, among a number of target genes, regulates glutaminase, the enzyme that converts glutamine into glutamate, a precursor of glutathione [20, 21]. Downregulation of MYCN in NB cells was expected to reduce the level of glutaminase, and subsequently glutathione, and sensitize cells to treatment. However, contrary to expectations, these cells were more resistant to apoptosis stimulation (Fig. 5b and Supplementary Fig. 4). We have shown previously that the resistance of TET21N cells lacking MYCN can be explained by lower level of transcription factor p53, a target of MYCN, which is responsible for the expression of various pro-apoptotic members of Bcl-2 family proteins [32]. Indeed, MYCN was shown to transcriptionally regulate $\mathrm{p} 53$ expression [33], leading to the hypothesis that p53 upregulation might be involved in MYCN-dependent sensitization to apoptosis [34]. Apparently, the absence of MYCN can make TET21N cells less sensitive to etoposide-mediated inhibition of Complex I. It has been shown that MYCN is involved in mitochondrial biogenesis [35]; moreover, inhibition of MYCN can cause respiratory chain impairment [36] resulting in lower oxygen consumption. Indeed, in our experiments, switching MYCN off suppressed OCR (Fig. 6a). Consequently, this should lessen the leakage of electrons upon inhibition of Complex I by etoposide, and formation of superoxide radical will be attenuated as compared to $\mathrm{MYCN}^{+}$TET21N cells (Fig. 6e).

Stimulation of ROS production via inhibition of various complexes of the mitochondrial respiratory chain can trigger apoptosis in tumor cells of various origins. Thus, rotenone-stimulated and antioxidant preventable HL-60 cell death, resulted from mitochondrial ROS production, was documented by various parameters, such as DNA fragmentation, cytochrome c release, and caspase 3 activity [37]. Suppression of Complex II by non-toxic doses of thenoyltrifluoroacetone, an inhibitor of Complex II, markedly augmented cell death induced by low doses of cisplatin [38]. Similarly, inhibition of Complex III by antimycin triggered apoptosis in PC12 cells [39]. The importance of the inhibition of respiratory chain complexes for apoptosis induction was further recognized with the finding that 
tumor necrosis factor (TNF)- $\alpha$ could inhibit Complex I of the mitochondrial respiratory chain [40].

Thus, the depletion of antioxidants or inhibition of pathways responsible for cellular antioxidant response can increase the efficiency of mitochondria targeting, enhance and strengthen antitumor therapy.

Acknowledgements Open access funding provided by Karolinska Institute. The work was supported by the Russian Science Foundation (Grant 19-14-00122). The work in the authors' laboratories is supported by Stockholm (181301) and Swedish (150371) Cancer Societies, the Swedish Childhood Cancer Foundation (PR2018-0058), and the Russian Foundation for Basic Research (18-04-00720 to VG and 18-315-00327 to PM).

\section{Compliance with ethical standards}

Conflict of interest The author declares that there is no competing interest.

Open Access This article is distributed under the terms of the Creative Commons Attribution 4.0 International License (http://creativeco mmons.org/licenses/by/4.0/), which permits unrestricted use, distribution, and reproduction in any medium, provided you give appropriate credit to the original author(s) and the source, provide a link to the Creative Commons license, and indicate if changes were made.

\section{References}

1. Kerr JF, Wyllie AH, Currie AR (1972) Apoptosis: a basic biological phenomenon with wide-ranging implications in tissue kinetics. Br J Cancer 26(4):239-257

2. Hanahan D, Weinberg RA (2011) Hallmarks of cancer: the next generation. Cell 144(5):646-674. https://doi.org/10.1016/j. cell.2011.02.013

3. Cory S, Adams JM (2002) The Bcl2 family: regulators of the cellular life-or-death switch. Nat Rev Cancer 2(9):647-656. https:// doi.org/10.1038/nrc883

4. Ola MS, Nawaz M, Ahsan H (2011) Role of Bcl-2 family proteins and caspases in the regulation of apoptosis. Mol Cell Biochem 351(1-2):41-58. https://doi.org/10.1007/s11010-010-0709-x

5. Vander Heiden MG, Cantley LC, Thompson CB (2009) Understanding the Warburg effect: the metabolic requirements of cell proliferation. Science 324(5930):1029-1033. https://doi. org/10.1126/science.1160809

6. Warburg O, Wind F, Negelein E (1927) The metabolism of tumors in the body. J Gen Physiol 8(6):519-530

7. D'Souza GG, Wagle MA, Saxena V, Shah A (2011) Approaches for targeting mitochondria in cancer therapy. Biochim Biophys Acta 1807(6):689-696. https://doi.org/10.1016/j.bbabi o.2010.08.008

8. Sarosiek KA, Letai A (2016) Directly targeting the mitochondrial pathway of apoptosis for cancer therapy using BH3 mimeticsrecent successes, current challenges and future promise. FEBS J 283(19):3523-3533. https://doi.org/10.1111/febs.13714

9. Hirsch HA, Iliopoulos D, Tsichlis PN, Struhl K (2009) Metformin selectively targets cancer stem cells, and acts together with chemotherapy to block tumor growth and prolong remission. Can Res 69(19):7507-7511. https://doi.org/10.1158/0008-5472. CAN-09-2994
10. Moreira PI, Custodio J, Moreno A, Oliveira CR, Santos MS (2006) Tamoxifen and estradiol interact with the flavin mononucleotide site of complex I leading to mitochondrial failure. J Biol Chem 281(15):10143-10152. https://doi.org/10.1074/jbc.M5102 49200

11. Kruspig B, Valter K, Skender B, Zhivotovsky B, Gogvadze V (2016) Targeting succinate:ubiquinone reductase potentiates the efficacy of anticancer therapy. Biochem Biophys Acta 1863(8):2065-2071. https://doi.org/10.1016/j.bbamc r.2016.04.026

12. Dong LF, Low P, Dyason JC, Wang XF, Prochazka L, Witting PK, Freeman R, Swettenham E, Valis K, Liu J, Zobalova R, Turanek J, Spitz DR, Domann FE, Scheffler IE, Ralph SJ, Neuzil J (2008) Alpha-tocopheryl succinate induces apoptosis by targeting ubiquinone-binding sites in mitochondrial respiratory complex II. Oncogene 27(31):4324-4335. https://doi.org/10.1038/onc.2008.69

13. Valko M, Rhodes CJ, Moncol J, Izakovic M, Mazur M (2006) Free radicals, metals and antioxidants in oxidative stress-induced cancer. Chem Biol Interact 160(1):1-40. https://doi.org/10.1016/j. cbi.2005.12.009

14. Brown GC, Borutaite V (2012) There is no evidence that mitochondria are the main source of reactive oxygen species in mammalian cells. Mitochondrion 12(1):1-4. https://doi.org/10.1016/j. mito.2011.02.001

15. Wise DR, Thompson CB (2010) Glutamine addiction: a new therapeutic target in cancer. Trends Biochem Sci 35(8):427-433. https://doi.org/10.1016/j.tibs.2010.05.003

16. DeBerardinis RJ, Mancuso A, Daikhin E, Nissim I, Yudkoff M, Wehrli S, Thompson CB (2007) Beyond aerobic glycolysis: transformed cells can engage in glutamine metabolism that exceeds the requirement for protein and nucleotide synthesis. Proc Natl Acad Sci USA 104(49):19345-19350. https://doi.org/10.1073/ pnas.0709747104

17. Le A, Lane AN, Hamaker M, Bose S, Gouw A, Barbi J, Tsukamoto T, Rojas CJ, Slusher BS, Zhang H, Zimmerman LJ, Liebler DC, Slebos RJ, Lorkiewicz PK, Higashi RM, Fan TW, Dang CV (2012) Glucose-independent glutamine metabolism via TCA cycling for proliferation and survival in B cells. Cell Metab 15(1):110-121. https://doi.org/10.1016/j.cmet.2011.12.009

18. Corvi R, Amler LC, Savelyeva L, Gehring M, Schwab M (1994) MYCN is retained in single copy at chromosome 2 band p2324 during amplification in human neuroblastoma cells. Proc Natl Acad Sci USA 91(12):5523-5527

19. Schwab M, Varmus HE, Bishop JM, Grzeschik KH, Naylor SL, Sakaguchi AY, Brodeur G, Trent J (1984) Chromosome localization in normal human cells and neuroblastomas of a gene related to c-myc. Nature 308(5956):288-291

20. Wise DR, DeBerardinis RJ, Mancuso A, Sayed N, Zhang XY, Pfeiffer HK, Nissim I, Daikhin E, Yudkoff M, McMahon SB, Thompson CB (2008) Myc regulates a transcriptional program that stimulates mitochondrial glutaminolysis and leads to glutamine addiction. Proc Natl Acad Sci USA 105(48):18782-18787. https://doi.org/10.1073/pnas.0810199105

21. Wang T, Liu L, Chen X, Shen Y, Lian G, Shah N, Davidoff AM, Yang J, Wang R (2018) MYCN drives glutaminolysis in neuroblastoma and confers sensitivity to an ROS augmenting agent. Cell Death Dis 9(2):220. https://doi.org/10.1038/s4141 9-018-0295-5

22. Lutz W, Stöhr M, Schürmann J, Wenzel A, Löhr A, Schwab M (1996) Conditional expression of N-myc in human neuroblastoma cells increases expression of alpha-prothymosin and ornithine decarboxylase and accelerates progression into S-phase early after mitogenic stimulation of quiescent cells. Oncogene 13(4):803-812

23. Sedlak J, Lindsay RH (1968) Estimation of total, protein-bound, and nonprotein sulfhydryl groups in tissue with Ellman's reagent. Anal Biochem 25(1):192-205 
24. Hunter DR, Haworth RA (1979) The $\mathrm{Ca}^{2+}$-induced membrane transition in mitochondria. I. The protective mechanisms. Arch Biochem Biophys 195(2):453-459

25. Takeyama N, Matsuo N, Tanaka T (1993) Oxidative damage to mitochondria is mediated by the $\mathrm{Ca}\left({ }^{2+}\right)$-dependent inner-membrane permeability transition. Biochem J 294(Pt 3):719-725

26. Cadenas E, Davies KJ (2000) Mitochondrial free radical generation, oxidative stress, and aging. Free Radic Biol Med 29(3-4):222-230

27. Valter K, Chen L, Kruspig B, Maximchik P, Cui H, Zhivotovsky B, Gogvadze V (2017) Contrasting effects of glutamine deprivation on apoptosis induced by conventionally used anticancer drugs. Biochim Biophys Acta 1864(3):498-506

28. Hemann MT, Lowe SW (2006) The p53-Bcl-2 connection. Cell Death Differ 13(8):1256-1259

29. DeBerardinis RJ, Chandel NS (2016) Fundamentals of cancer metabolism. Sci Adv 2:e1600200

30. Gorrini C, Harris IS, Mak TW (2013) Modulation of oxidative stress as an anticancer strategy. Nat Rev Drug Discov 12:931-947

31. Zou Z, Chang H, Li H, Wang S (2017) Induction of reactive oxygen species: an emerging approach for cancer therapy. Apoptosis 22(11):1321-1335

32. Kruspig B, Nilchian A, Bejarano I, Orrenius S, Zhivotovsky B, Gogvadze V (2012) Targeting mitochondria by $\alpha$-tocopheryl succinate kills neuroblastoma cells irrespective of $\mathrm{MycN}$ oncogene expression. Cell Mol Life Sci 69(12):2091-2929

33. Eischen CM, Weber JD, Roussel MF, Sherr CJ, Cleveland JL (1999) Disruption of the ARF-Mdm2-p53 tumor suppressor pathway in Myc-induced lymphomagenesis. Genes Dev 13(20):2658-2669

34. Chen L, Iraci N, Gherardi S, Gamble LD, Wood KM, Perini G et al (2010) p53 is a direct transcriptional target of MYCN in neuroblastoma. Cancer Res 70(4):1377-1388
35. Wahlström T, Henriksson MA (2015) Impact of MYC in regulation of tumor cell metabolism. Biochim Biophys Acta 1849(5):563-569

36. Zirath H, Frenzel A, Oliynyk G, Segerström L, Westermark UK, Larsson K, Munksgaard Persson M, Hultenby K, Lehtiö J, Einvik C, Påhlman S, Kogner P, Jakobsson PJ, Henriksson MA (2013) MYC inhibition induces metabolic changes leading to accumulation of lipid droplets in tumor cells. Proc Natl Acad Sci USA 110(25):10258-10263

37. Li N, Ragheb K, Lawler G, Sturgis J, Rajwa B, Melendez JA, Robinson JP (2003) Mitochondrial complex I inhibitor rotenone induces apoptosis through enhancing mitochondrial reactive oxygen species production. J Biol Chem 278(10):8516-8525

38. Kruspig B, Valter K, Skender B, Zhivotovsky B, Gogvadze C (2016) Targeting succinate:ubiquinone reductase potentiates the efficacy of anticancer therapy. Biochim Biophys Acta 1863(8):2065-2071

39. Lanju X, Jing X, Shichang L, Zhuo Y (2014) Induction of apoptosis by antimycin A in differentiated PC12 cell line. J Appl Toxicol 34(6):651-657

40. Higuchi M, Proske RJ, Yeh ET (1998) Inhibition of mitochondrial respiratory chain complex I by TNF results in cytochrome $\mathrm{c}$ release, membrane permeability transition, and apoptosis. Oncogene 17(19):2515-2524

Publisher's Note Springer Nature remains neutral with regard to jurisdictional claims in published maps and institutional affiliations. 